\title{
Article \\ A Method to Count Olive Trees in Heterogenous Plantations from Aerial Photographs
}

\author{
Yann H. Chemin ${ }^{1, *}$ and Pieter S.A. Beck ${ }^{2}$ \\ 1 Independent researcher, Plumergat, France; yann.chemin@gmail.com \\ 2 European Commission, JRC, Ispra, Italy; pieter.beck@ec.europa.eu \\ * Correspondence: yann.chemin@gmail.com; Tel.: +33-7-8385-5234
}

\begin{abstract}
Olive trees have been of economic and cultural value since pre-Roman times, and continue to dominate landscapes and agriculture in many mediterranean regions. Recent mass losses of olive trees in Southern Italy due to an exotic plant pathogen highlight the need for methods that to monitor the olive trees in a landscape or region operationally. Here, we develop a method for counting olive trees from aerial photographs and test it in areas with a high diversity of olive tree ages, sizes, and shapes. This heterogeneity complicates tree counting as centennial trees often have crowns that are split into multiple segments, resembling multiple crowns, while nearby crowns often form a semi-closed canopy comprising multiple trees. Comparisons with reference counts in two 20 ha sites and over three different years indicate the automated counts tend to be reasonably accurate (median error $13 \%, n=6$ ), but heavily influenced by a few olive orchards with particularly high planting densities and a relatively closed canopy in which distinguishing individual trees is challenging. Overall, the algorithm estimated tree densities well (counting 82 to 109 trees/ha versus 87 to 104 trees/ha in the reference counts), indicating the method is suitable to track the number of olive trees over large areas.
\end{abstract}

Keywords: tree counting; olive trees; Xylella fastidiosa; morphology; algorithms; image processing; tree crowns

\section{Introduction}

Since its detection in southern Italy in late 2013, the plant pathogen Xylella fastidiosa has steadily spread northwards through the Apuglia region of Italy causing extensive damage to olive trees, which dominate local agriculture (Figure 1, [1]). The impact on the landscape and economy is conspicuous, with rapid and extensive die-off of the olive tree crowns in the most affected regions. The landscape layout, in which olive orchards dominate, makes halting the epidemic particularly challenging [2]. Recent findings of Xylella fastidiosa on the Balearic islands and on mainland Spain, support the theory that the pathogen could affect the entire Mediterranean region [3]. In response to the Xylella fastidiosa outbreak, the EU has put in place an extensive range of eradication and containment measures [4] which in some regions call for the felling of infected trees, and in certain cases also of healthy trees in their vicinity. 


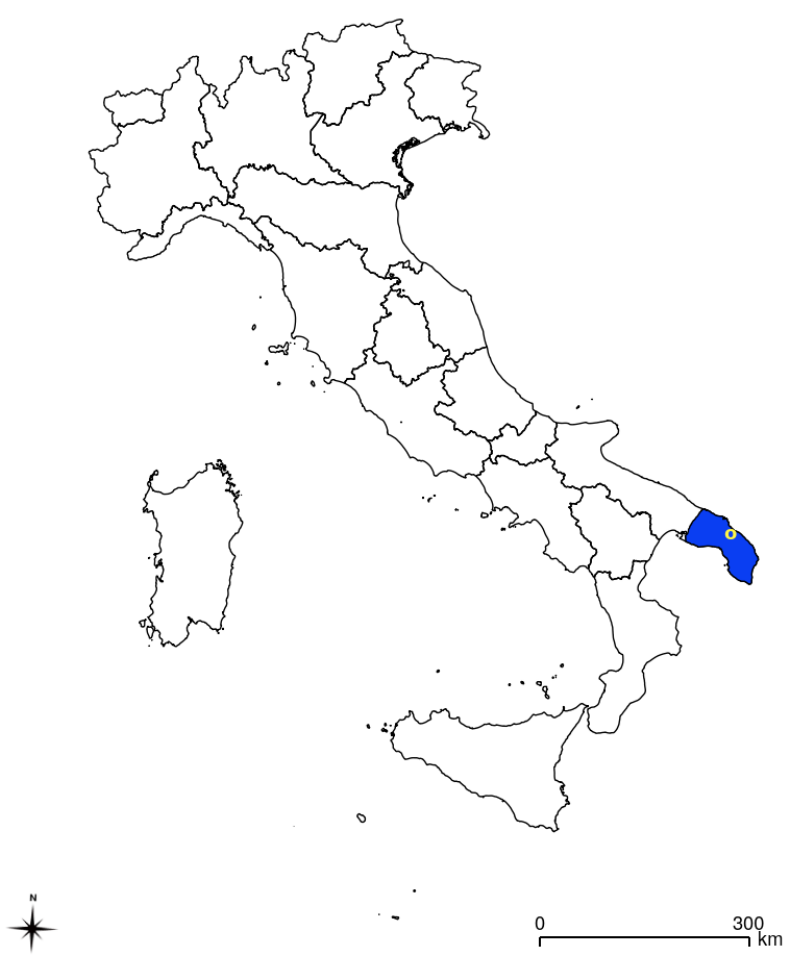

Figure 1. Location of the study area in Italy (on data from gadm.org). The dark blue area indicates the area in the Italian region of Apuglia where Xylella fastidiosa is present. The dot indicates the study area.

The extent of the damage caused by Xylella fastidiosa is currently poorly understood as the anticipated impacts on regional olive oil production have not yet been reported, thus preventing an assessment of the economic impact. Such assessment could be expedited if the number of trees lost to the epidemic (either directly or indirectly, through preventive phytosanitary measures) were monitored. However, this number is currently unknown. Moreover, information on the number and location of olive trees lost as a result of the Xylella fastidiosa outbreak is required to understand the spread of the pest thus far, and to inform epidemiological models that may simulate it [5]. Knowing the impact of the epidemic on olive tree stocks can also support planning of the response to the emergency, e.g. by informing a more precise evaluation of the impact of the possible containment measures. Finally, an inventory of olive trees could be used to estimate and compensate losses to the olive sector. Given the abundance of olive trees in the Apuglia region, and the high number of landowners, automated analysis of remotely sensed images could generate such inventory most efficiently.

Remote sensing based methods for tree counting generally combine image analysis methods with either probabilistics or some form of mathematical morphology (for a review, see[6]) . Most of these studies analyze Red-Green-Blue-NIR or other multispectral data from very high resolution satellite data, but see [7] for an example of the use of both radar and passive optical data for counting trees of various species, including olives. In contrasts, studies for wall-to-wall detection of individual trees in aerial photographs are rare, despite the abundance of such data owing to their use in photogrammetry. Reasons for this gap might be that geometric consistency is prioritized over radiometric accuracy in the production of orthophotos, the cost of the images, and their data volume.

The OLICOUNT model [8] [9] was developed for counting olive trees in pansharpened satellite images of sub-meter resolution. It relied on a combination of spectral thresholding (i.e. using the spectral characteristics of trees), region growing, and tests based on morphological parameters of regions (i.e. using the morphology of individual trees). Furthermore, the model was initially a semi-automatic, and optimized for individual agricultural parcels, rather than for wall-to-wall 
mapping. [10] studied Ikonos and Quickbird images for morphometric analysis, using nonlinear diffusion to smooth the images while preserving relevant contrasts, before identifying local spatial maxima of the Laplacian of the image to extract the shapes of olive trees. Similarly, [11] designed a model, the Arbor Crown Enumerator (ACE), to identify and count tree crowns on the Greek Island of Crete. It works with multispectral information of a Quickbird $(70 \times 70 \mathrm{~cm})$ image, thresholding its Red band data and Normalized Difference Vegetation Index (NDVI). For crown separation, it uses the Laplacian of the Gaussian (LOG) blob detection method. [12] classified Ikonos-2 imagery with a Gaussian Process Classifier to separate olive orchards from other land use classes. The elements in the orchards that might represent individual olive trees and fit predefined size criteria were then counted using an automatic procedure, defining each object as one tree. [13] instead used image computer vision and probabilistics on VHR satellite imagery. In many landscapes, particularly intensively managed ones, olive trees are planted along regular grids and are even-aged. As a result, in very-high-resolution satellite images of these areas, such as from Ikonos, Quickbird, Orbview, or Worldview satellites, olive trees have a very constant size, similar shape, and follow a reticular layout. These properties translate into the identifiable co-linearity patterns and patch sizes that have been used thus far to identify olive orchards in satellite images.

The resolution of satellite data can be insufficient to reliably discriminate individual olive trees when they follow an irregular grid, particularly when they vary greatly in size and shape, as occurs in the less intensively managed olive orchards of Southern Apuglia. The farming in this region is characterized by the prevalence of centennial olive trees with crowns reaching $10 \mathrm{~m}$ in diameter, sometimes consisting of two or more major clusters of branches, that in a top-down view may resemble separate crowns. Furthermore, these crown sections, as well as crowns of smaller trees, often reach the crowns of neighbouring trees (Figure 2, bottom panel). In such a canopy, it is difficult to distinguish individual trees based on the top-down view that aerial images typically provide (Figure 3 ).

Here, we build on image analysis techniques from different scientific fields to develop a method to automatically detect and count individual olive tree crowns in aerial images. We apply the method in an area where olive trees are planted irregularly and are of highly variable sizes, including some of which are old and have very heterogenous crowns. The errors in the automatically obtained counts are then quantified using photo-interpreted reference data. To further assess the robustness of the new method, the validation is replicated using images acquired by different sensors with their own spectral specifications, and taken on different dates and at different spatial resolutions. 


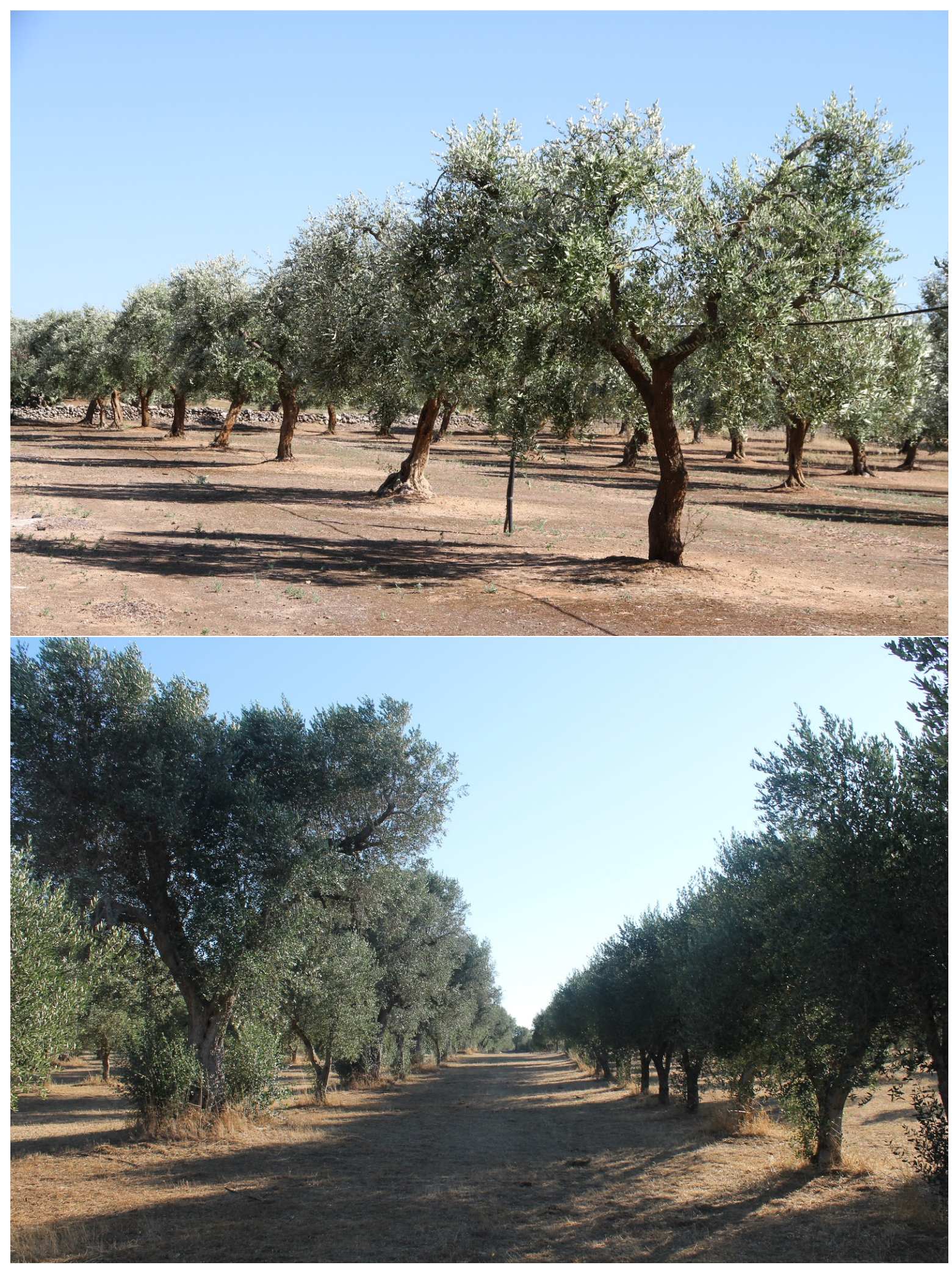

Figure 2. Examples of olive trees near the study area, with crowns dominated by few large branches (top panel) and with crowns of neighbouring trees touching each other (bottom panel) 


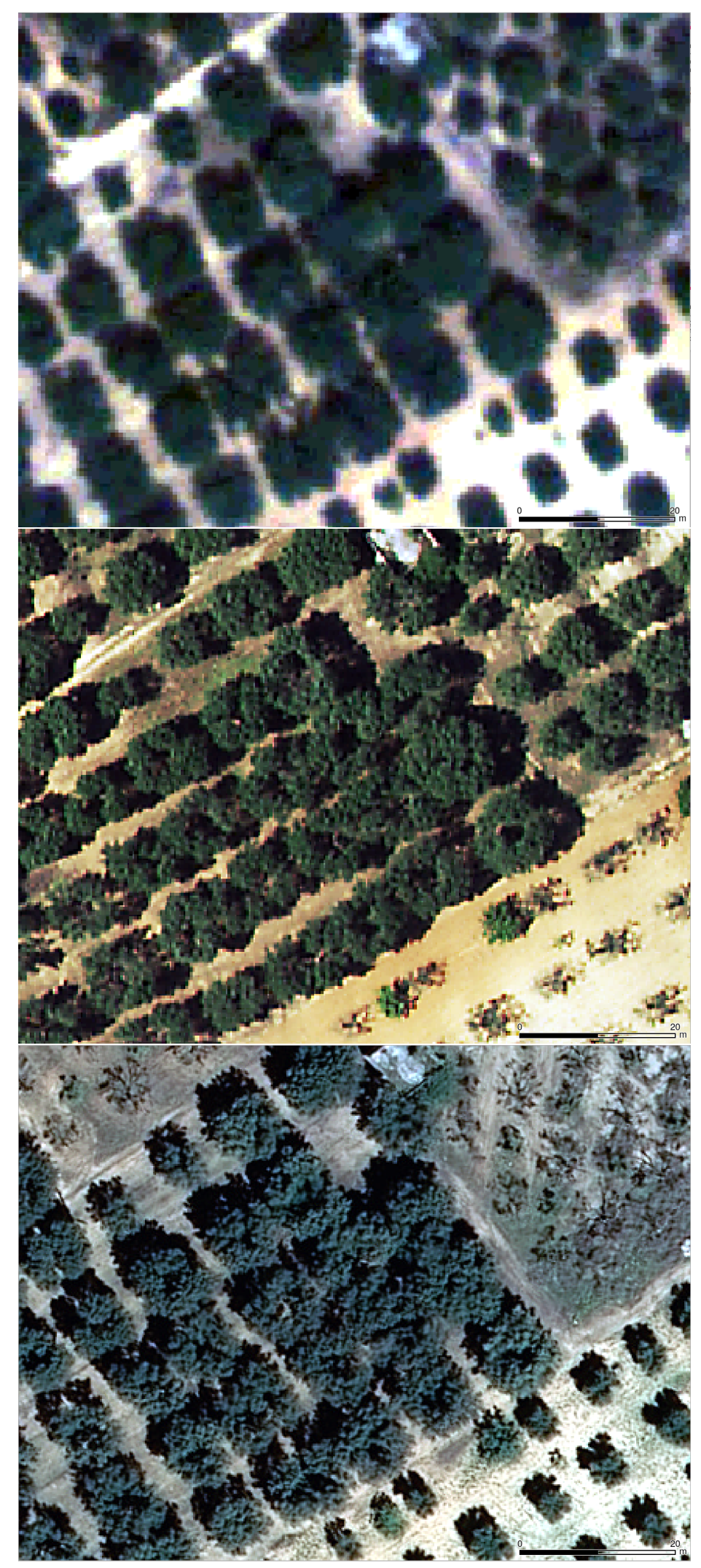

Figure 3. True colour samples of aerial photographs of olive orchards in the study area with $50 \mathrm{~cm}$ (top), $30 \mathrm{~cm}$ (middle), and $20 \mathrm{~cm}$ resolution (bottom), and collected in 2013, 2015, and 2016, respectively. The individual samples measure $80 \mathrm{~m}$ across and illustrate the heterogeneity of the orchards, including, near to each other, trees with large crowns that form a semi-closed canopy with adjacent trees, trees with crowns that are split into two or more clusters of branches, trees of varying sizes, and trees that have been recently pruned. In addition, they illustrate differences in the understorey and shadowing depending on phenology and image acquisitions times, as well as effects of image resolution. 


\section{Data and Software}

We analyzed four RGB-infrared aerial images: 1) A $50 \mathrm{~cm}$ resolution image acquired as part of a campaign in May-June 2013 with Leica ADS40 and ADS80 cameras, 2) a $30 \mathrm{~cm}$ resolution image acquired on the 30th of May 2015 with a Leica ADS100 camera, and 3) a $20 \mathrm{~cm}$ image acquired between the 7th and 25th of May 2016 at $20 \mathrm{~cm}$ with a Leica DMC III camera.

The ADS100 is a large-format photogrammetric camera with a sensor containing 13 CCD lines with 20,000 pixels each in three line groups (Forward, Nadir, Backward) installed in different positions on the focal plane to provide various along track viewing angles: nadir panchromatic (PAN; $2^{\circ}$ ), nadir R, G, B and NIR $\left(0^{\circ}\right)$, backward PAN $\left(14^{\circ}\right)$, backward R, G, B and NIR $\left(16^{\circ}\right)$ and forward PAN $\left(27^{\circ}\right)$. The camera is gyro-stabilised via a mount with adaptive control. The ADS40 and ADS80 are precursors of the ADS100. The ADS40 relies on a 12-bit Dynamic range CCD and produces 8-bit compressed output. The CCD has a total of 12 lines, four panchromatic, and 8 multispectral, of 12,000 pixels each. The ADS80 improves on the ADS40 by adding double spectra lines for each of the visible and the NIR bands, thereby increases radiometer accuracy. The sensor of the DMC III camera has 25,728 pixels across track and 14,592 pixels along track. It has four colour channels (R, G, B, NIR) recording in 14-bit. It was flown at an altitude of 5000 m.a.s.l. to generate images with a $20 \mathrm{~cm}$ pixel size.

Our study area comprises two 400 ha rectangular zones in Southern Puglia (near $40.5^{\circ} \mathrm{N}, 18.0^{\circ} \mathrm{E}$, Figure 1, and referred to as zone 1 and zone 2) that are dominated by olive orchards and were imaged in 2013, 2015, and 2016. First reports of trees affected by Xylella fastidiosa near the study area merged in the second half of 2015 (Puglia Province, 2016). The few parcels in the study area that are not dedicated to olive farming, but to vineyards, roads or buildings, were masked from the analysis, to retain 365 ha in zone 1 and 331 ha in zone 2 for analysis. The masking was based on a high-resolution (1:10 000) map of olive orchards obtained from the regional authorities through its online GIS portal (Puglia Province, 2016). This soil usage map itself is based on aerial photos taken in $2011 \mathrm{with} 50 \mathrm{~cm}$ resolution.

The analysis relied on open source software packages for image manipulation and processing: Fiji [14], GRASS GIS [15] and GDAL [16]. Additional image scripts were programmed in C [17], OpenMP [18], BASH Shell [19], and Python [20] depending on complexity, processing time, and core parallelisation possibilities.

\section{Methods}

\subsection{Image segmentation}

The images were first processed to NDVI, then segmented based on objects following on Niblack's thresholding method [21] and Sauvola binarization techniques [22] Figure reffig4 to distinguish tree crowns from the background. Next, a binary watershed analysis, using the Euclidian distance map for each object, separated olive trees with overlapping crowns using a microbiological cell counting algorithm as seen in [23], Figure 5. This segmentation approach has been successfully applied to hyperspectral imagery by [24] and to thermal imagery for water stress detection [25].

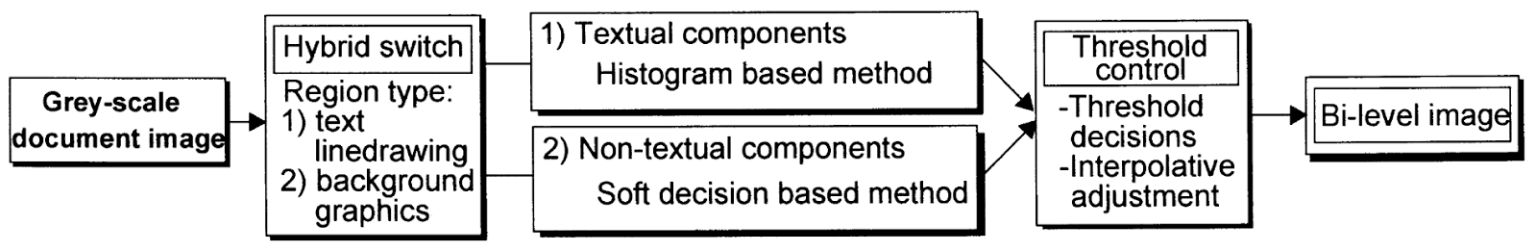

Figure 4. Sauvola algorithm overview (from [22]) 
a
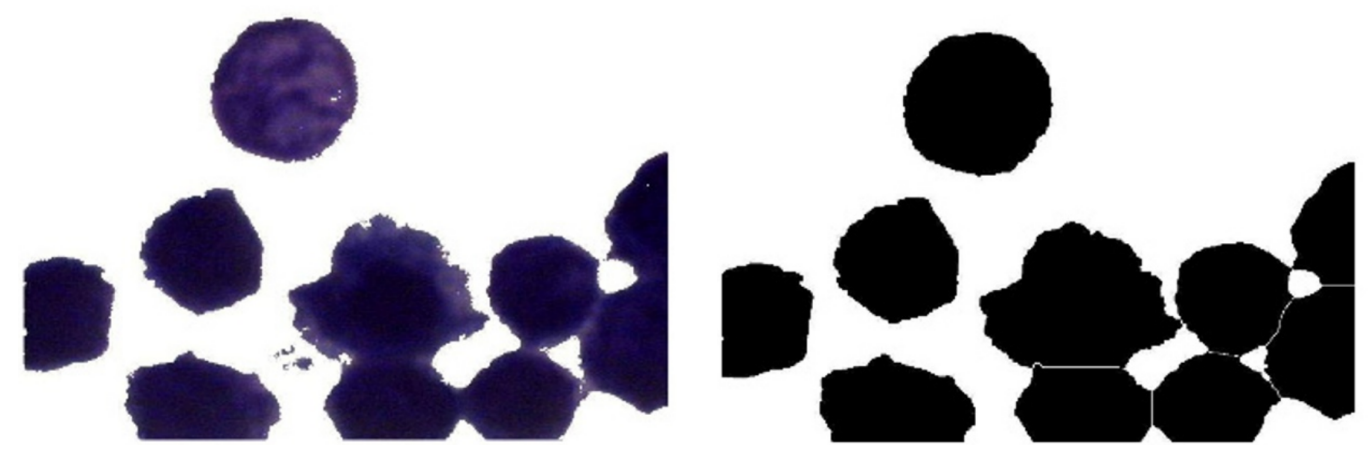

Figure 5. (a) Image of giemsa stained section of Hep2-treated cells (b) The same view after thresholding the image color and applying watershed-based binarization of the 8-bit image (from [23])

The watershed analysis tended to split heterogenous olive tree crowns (Figure 6a) into different sub-crown segments(Figure 6b). This occurred particularly in older olive trees, in which few large branches often dominate the crown. To partly address this, segments separated by a line of single pixels in any direction (Figure 6c) were reconnected. This approach was designed to reduce the number of heterogenous crowns split into multiple segments while avoiding the merger of segments belonging to different trees.
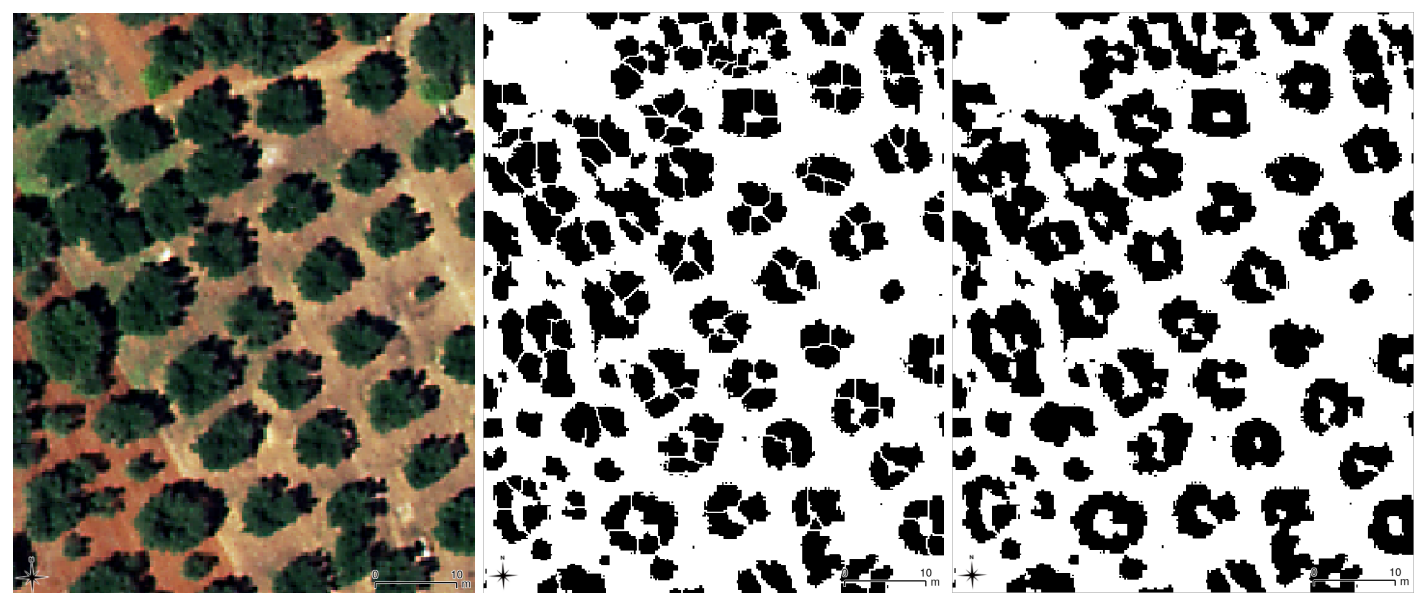

Figure 6. True colour composite of original image (a), tree crown segments identified by object-based segmentation and watershed analysis (b), and merger of nearby crown segments (c). The depicted area measures $60 \mathrm{~m}$ across.

Next, we removed segments that were smaller than a predefined area corresponding to the smallest crowns $\left(<0.64 \mathrm{~m}^{2}\right)$, and identified those that were too big to represent a single crown $(>18$ $\mathrm{m}^{2}$, see section Identifying the centres whose crowns touch each other). The remaining segments were then assigned individual IDs, so they could be counted (Figure 7). These operations were carried out in GRASS GIS [15]. 


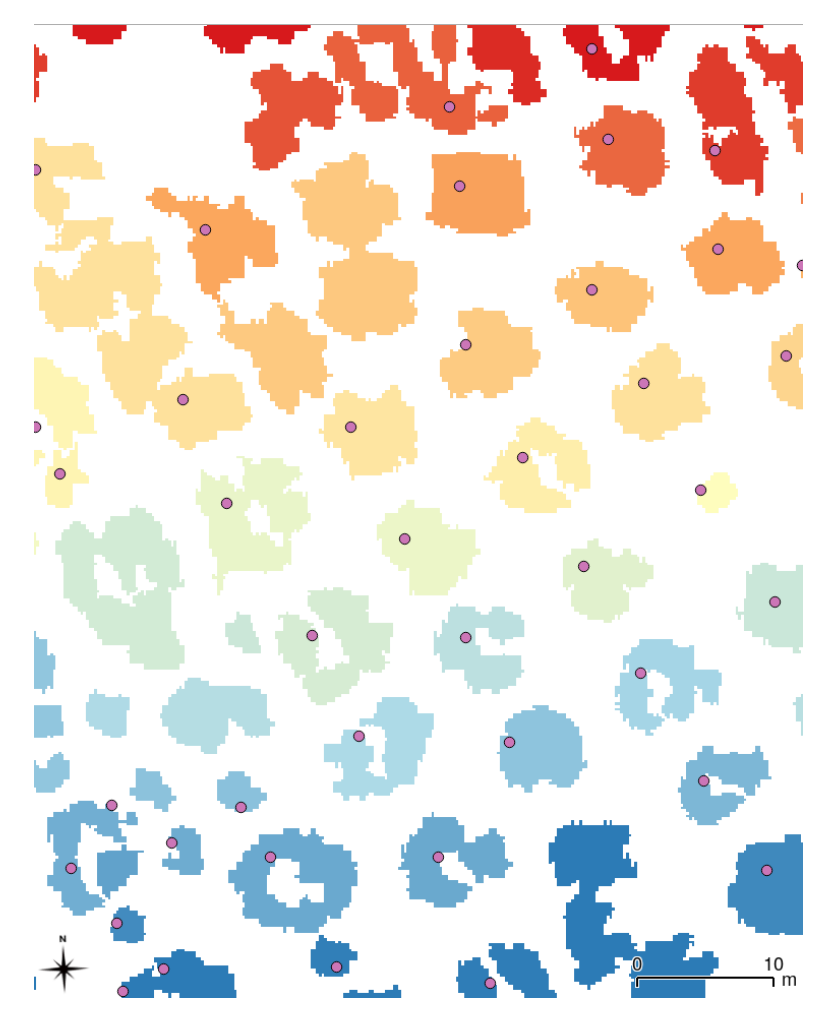

Figure 7. Centres of segments representing individual, isolated, tree crowns. No centres are shown for segments larger than $18 \mathrm{~m}^{2}$ as they are analyzed further to determine if they encompass multiple tree crowns.

\subsection{Identifying the centres of isolated tree crowns}

Southern Apuglia has a high prevalence of particularly large old olive trees, compared to regions with more recent or intense olive cultivation. Because of their fragmented crowns, many of these centennial olive were initially represented by multiple segments, organized around the tree's trunk. To identify when segments in the image belonged to the same tree, and avoid double-counting of trees, we developed a new approach to locate canopy centers from crown segments. The method drew on [26] who uses three points to assess the rim of craters in planetary sciences; it estimates and averages the circle centres based on all sufficiently separated triplets of points located on the outer boundary of segments. The actual algorithm is solving three-point circle equations with two unique unknowns, namely the $\mathrm{x}$ and $\mathrm{y}$ coordinate of the center of the circle the points may fall on. This process was iterated over all points belonging to a segment's border, except for points that were less than two pixels apart from each other. For each segment, the different derived centres were then averaged to the point that had the smallest summed Euclidean distance to all points.

Crowns of older trees, with highly heterogenous crowns, tend to produce multiple crescent-shaped segments, oriented towards trunk, which often has no branches immediately above it (Figure 8). In such cases, our method derives one or more centres (depending on the number of segments belonging to the crown), in close proximity to each other (Figure 8). Therefore, our algorithm scans through all the center points derived in the previous steps, and replaces those that are within a predefined Euclidian distance from each other, with their average representing a single tree's centre (Figure 6b). Here, this distance was set to $2 \mathrm{~m}$, as it represents a lower limit to the spacing between trees in the study area. 
Figure 8. Centres estimated for individual segments (stars) were merged (dot), if they were less than 2 $\mathrm{m}$ from each other, as they are likely to belong to a single tree, with fragmented crown and no branches right above the crown.

\subsection{Identifying the centres of trees whose crowns touch each other}

When a segment identified as a potential tree crown was larger than $18 \mathrm{~m}^{2}$, it was considered to be a merger of multiple crowns. This occurred particularly in orchards dominated by older olive trees, some of which have canopies reaching $10 \mathrm{~m}$ in diameter. To avoid underestimating the number of such trees, we investigated how to separate such crowns in the analysis; the challenge was made more difficult by the fact that older trees often lose their branches in the center of the crown generating a hole in the crown, or an open-crescent-shaped crown (Figure 8). To address this, we developed a mathematical morphology algorithm and tuned it to the characteristics of those large, and often irregular, fused tree crowns. The algorithm has several parts, including a repeated closing operator (dilation + erosion). It is adapted to a preset observed tree crown width, in order to fill the inner islands mentioned above that are caused by the absence of branches immediately above the tree trunk. This operator has the effect of smoothing the edges of the segment, and rounding it, causing the inner island to gradually fill in. Finally, an erosion operator is iterated until sub-areas are sufficiently reduced to be separable as single pixels (Figure 9). The coordinates at the centres of these pixels are then extracted to be used in the tree counting. 


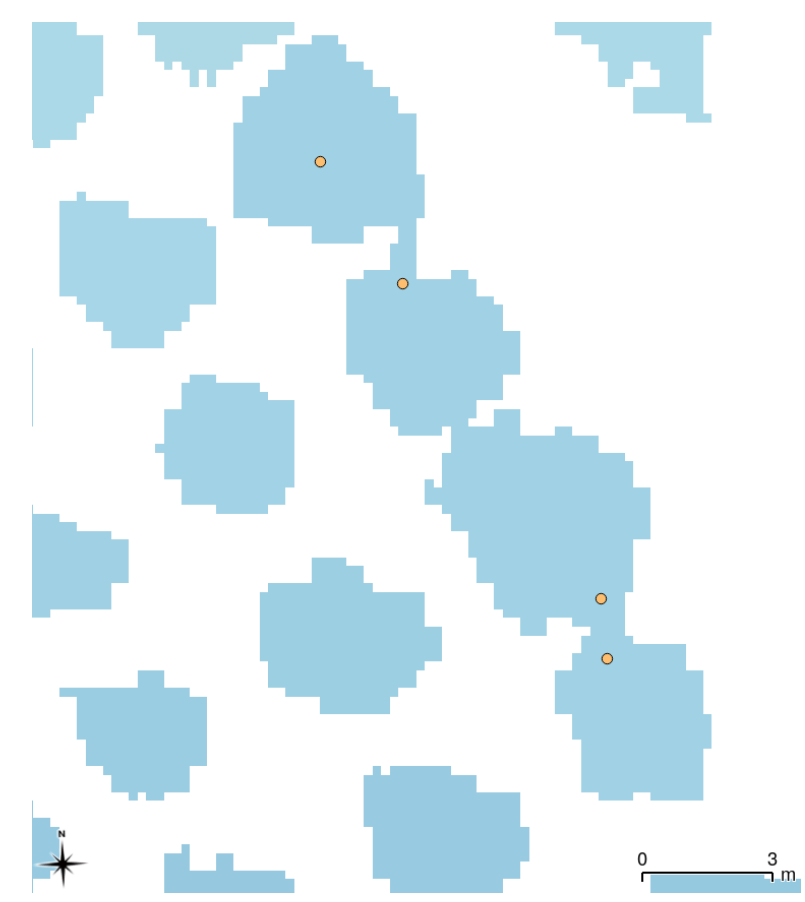

Figure 9. Centres of olive tree crowns detected by a sequence of repeated closing and erosion operators within an image segment encompassing multiple trees.

Finally, the coordinates of the centres of large trees with touching crowns were combined with those derived earlier for the centres of smaller (less than $8 \mathrm{~m}^{2}$ ), isolated, tree crows. The complete coordinate set was then intersected with the high-resolution $(1: 10,000)$ digital map of olive orchards in the Puglia region [27]. This intersection had the effect of removing artifacts and non-olive crowns from the results and from the final counts of olive trees.

\subsection{Error assessment}

To generate reference data for error assessment, we performed a visual tree count in a subset of the two zones comprising the study area: $5 \%$ or 20 ha, of each 400 ha zone was randomly selected as 20 square plots sampled from a regular one-ha grid (Figure 10). In each of these areas, all olive trees were counted through photo-interpretation of the aerial images. The total number of olive trees visually counted in the 20 ha area was then compared with the automated olive tree count in that same area, as an indication of the error in the latter.

Our algorithm comprises two main components, a first one that assumes all detected crowns represent single trees and is thus suited for counts isolated trees and a second one that counts trees whose crown forms a continuous canopy with neighbouring trees trees. During error assessment, we compared both the counts obtained by the first component, and by the combination of the two components to the reference data. 


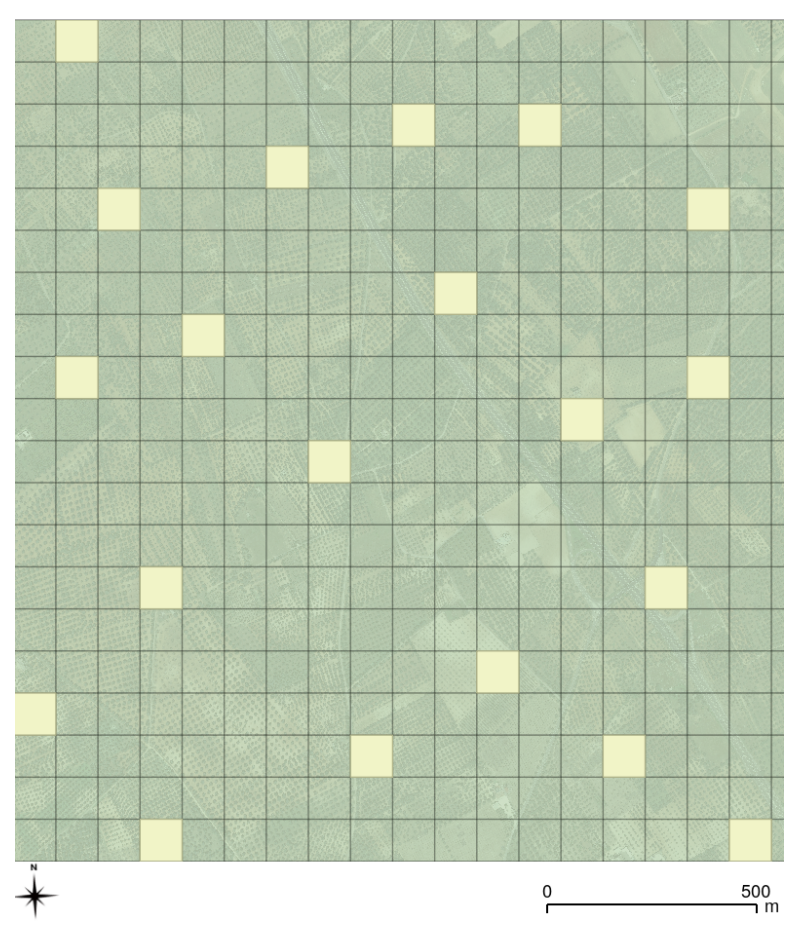

Figure 10. 1 ha grid overlaid on zone 1 of the study area, and the 20 randomly sampled areas, representing $5 \%$ of the area, used for error assessment.

\section{Results}

Our automated algorithm counted between 32,600 and 42,394 olive trees in the ca 400 ha zones of the study area, depending on the zone and year of the images, translating in densities of 82 to 109 trees/ha (Table 1). The latter is close to 87 to 104 tree/ha densities in the 20 ha area reference areas where olive trees were visually counted.

Implementing only the first component of the algorithm, which counts crowns assumed to represent single trees, underestimates the total number of trees by $10 \%$ to $16 \%$, except for one zone-year combination where it overestimated the number by 3\%. The 20 ha reference area in zone 1 contained more trees than the reference area in zone 2 in all years, despite contrasting interannual variation in the number of trees in both. The automated counts of isolated trees correctly reflected this ranking, both between zones (counting more trees in zone 1 than in zone 2), and between years (detecting, between 2013 and 2016, the increase in the number of trees in zone 1 and the decrease in zone 2).

Separating crowns that form single canopies with neighbouring trees (i.e. the second component of the algorithm), increases the counts by 1\% to 40\% (in zone 2 year 2013, and zone 2 year 2015, respectively). In the latter case, however, this is an exaggeration, as it led to an overestimation of the total number of trees by $27 \%$. In two of the six year-zone combinations the inclusion of the crown splitting reduced the absolute error of the tree counts, in the others it caused an overestimation of the total number of trees. 
Table 1. Olive tree counts in the two ca 400 ha zones in Apuglia estimated in three different years. Errors are expressed as the difference between the number of olive trees retrieved by the automated tree counting algorithm, and the number of trees visually counted by photo-interpretation in a randomly sampled 20 ha validation area. Positive errors indicate overestimation by the automated algorithm. Tree densities are expressed in trees/ha, using the total area of olive orchards in the two zones (365 ha for zone 1 and 331 ha for zone2).

\begin{tabular}{|c|c|c|c|c|c|c|c|c|}
\hline \multirow[t]{3}{*}{ Zone } & \multirow[t]{3}{*}{ Year } & \multicolumn{4}{|c|}{ Random sample of $5 \%$ of the study area } & \multirow{2}{*}{\multicolumn{3}{|c|}{$\begin{array}{l}\text { Entire study area } \\
\text { automated count }\end{array}$}} \\
\hline & & \multirow{2}{*}{$\begin{array}{l}\text { Reference } \\
\text { count (n) }\end{array}$} & \multicolumn{3}{|c|}{ automated count } & & & \\
\hline & & & $\begin{array}{l}\text { Isolated } \\
\text { tree } \\
\text { crowns (n, } \\
\text { error) }\end{array}$ & $\begin{array}{l}\text { Trees with } \\
\text { touching } \\
\text { crowns } \\
\text { (n) }\end{array}$ & $\begin{array}{l}\text { All trees } \\
(\mathrm{n}, \text { error) }\end{array}$ & $\begin{array}{l}\text { Isolated } \\
\text { tree } \\
\text { crowns: } \\
\text { nr of trees } \\
\text { (trees } / \text { ha) }\end{array}$ & $\begin{array}{l}\text { Trees with } \\
\text { touching } \\
\text { crowns: } \\
\text { nr of trees } \\
\text { (trees/ha) }\end{array}$ & $\begin{array}{l}\text { All trees: } \\
\text { nr of trees } \\
\text { (trees } / \text { ha) }\end{array}$ \\
\hline Zone 1 & 2013 & 1,737 & $\begin{array}{c}1,558 \\
(-10 \%)\end{array}$ & 461 & $\begin{array}{c}2,019 \\
(+14 \%)\end{array}$ & $\begin{array}{c}33,480 \\
(92)\end{array}$ & $\begin{array}{c}8,914 \\
(24)\end{array}$ & $\begin{array}{c}42,394 \\
(117)\end{array}$ \\
\hline Zone 1 & 2015 & 2,061 & $\begin{array}{c}1,738 \\
(-16 \%)\end{array}$ & 244 & $\begin{array}{l}1,982 \\
(-4 \%)\end{array}$ & $\begin{array}{c}32,644 \\
(89)\end{array}$ & $\begin{array}{c}3,360 \\
(9)\end{array}$ & $\begin{array}{c}36,004 \\
(99)\end{array}$ \\
\hline Zone 1 & 2016 & 2,077 & $\begin{array}{l}1,760 \\
(-15 \%)\end{array}$ & 585 & $\begin{array}{c}2,345 \\
(+13 \%)\end{array}$ & $\begin{array}{c}32,386 \\
(89)\end{array}$ & $\begin{array}{c}11,230 \\
(30)\end{array}$ & $\begin{array}{c}43,616 \\
(120)\end{array}$ \\
\hline Zone 2 & 2013 & 1,833 & $\begin{array}{l}1,883 \\
(+3 \%)\end{array}$ & 28 & $\begin{array}{l}1,911 \\
(+4 \%)\end{array}$ & $\begin{array}{c}36,145 \\
(109)\end{array}$ & $\begin{array}{c}1,583 \\
(5)\end{array}$ & $\begin{array}{c}37,728 \\
(114)\end{array}$ \\
\hline Zone 2 & 2015 & 1,826 & $\begin{array}{l}1,656 \\
(-10 \%)\end{array}$ & 669 & $\begin{array}{c}2,325 \\
(+27 \%)\end{array}$ & $\begin{array}{l}30,208 \\
(91)\end{array}$ & ${ }^{2,392}$ & $\begin{array}{l}32,600 \\
(99)\end{array}$ \\
\hline Zone 2 & 2016 & 1,791 & $\begin{array}{c}1,594 \\
(-11 \%)\end{array}$ & 526 & $\begin{array}{c}2,120 \\
(+18 \%)\end{array}$ & $\begin{array}{c}28,268 \\
(85)\end{array}$ & $\begin{array}{c}6,642 \\
(20)\end{array}$ & $\begin{array}{c}34,910 \\
(106)\end{array}$ \\
\hline
\end{tabular}

Total olive tree counts for the study area indicate a greater number of trees in Zone 1 than in Zone 2 (40,671 and 35,079 trees, respectively, averaged over the three years). This difference exceeds the difference in area between the two zones, leading to a greater density of trees estimated for Zone 1 (111 trees/ha versus 106 trees/ha). When assuming the error rates estimated for the reference areas, the difference in tree numbers between the zones of the study area is significant in 2015 and 2016, but not in 2013 (Figure 11).

Olive tree counts in both of the zones of the study area reach a minimum in 2015 . This is unlikely to be an artifact of the differences between images, as this pattern is not present in the automated tree counts in the 20 ha reference areas. Instead, once validation-based error rates are applied, the difference only persists in Zone 2 (Figure 11).

The number of isolated trees counted in Zone 2 decreases by 22\% between 2013 and 2016, compared to $3 \%$ in Zone 1 (for the reference area this is $15 \%$ and $-13 \%$, respectively). As the isolated trees tend to be smaller and younger, these differences, which are in line with the reference tree counts, might reflect a difference in management (and particularly the timing of pruning) between these two zones. Uncertainty increases, however, when the counts of trees forming a single canopy are included, indicating the difficulty of resolving these cases. 


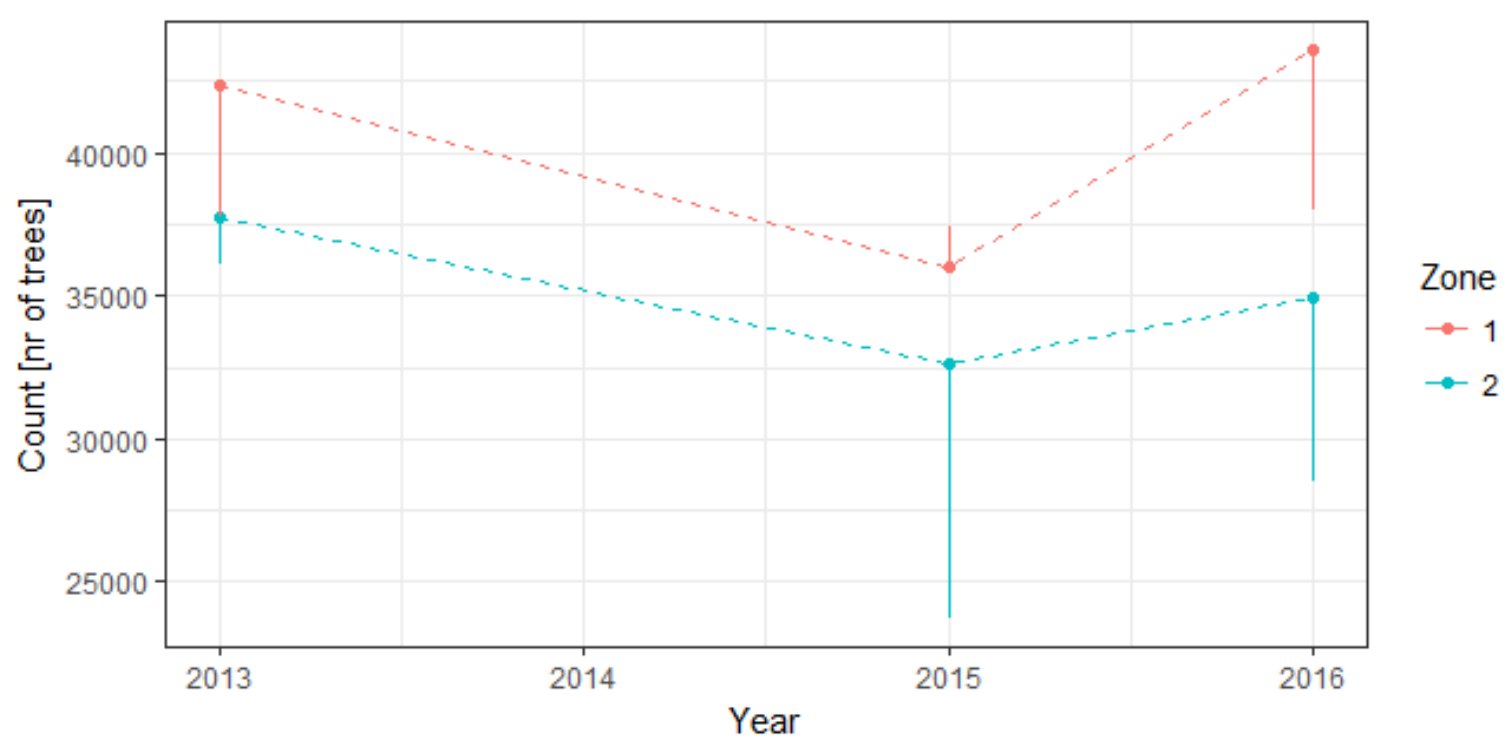

Figure 11. Olive tree counts in the two zones comprising the study areas based on orthophotos of 2013, 2015 , and 2016. Vertical bars are based on the \% error estimated for each zone-year combination based on validation data collected by photo-interpretation over subsets of the zones, representing $5 \%$ of their areas

Errors of the olive tree counting algorithm varied with observed tree density (Figure 12). Among the 20 one-ha square plots that made up the reference area in Zone 1 in 2015, tree densities between 100 and 120 trees/ha, which correspond to plantations of well-spaced intermediately-aged trees, were most prevalent ( 8 of 20 plots). In these settings, errors averaged $-1.5 \%$ (standard deviation $=0.07 \%, \mathrm{~N}=$ 8). Areas of lower tree densities are characterized by older trees, with discontinuous crowns that often touch those of neighbouring trees, generating a more complex and variable canopy architecture. In these settings (< ca. 80 tree/ha) the algorithm relies on its second component and model performance is lower on average, and more variable. Areas with very high tree density ( $>170$ trees/ha) are rare; one plot had a density of 178 trees/ha and one, in which citrus trees were planted between the olive trees, had a density of 334 trees/ha. In both these cases, tree numbers were greatly underestimated (by ca. $40 \%$ ). While they do not present a large portion of the total area, or a large fraction of the olive crop, these high-density plantations have an outsized effect on the errors calculated for the olive tree counting algorithm. 
a)

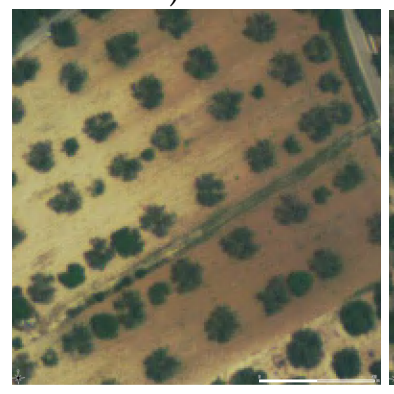

b)

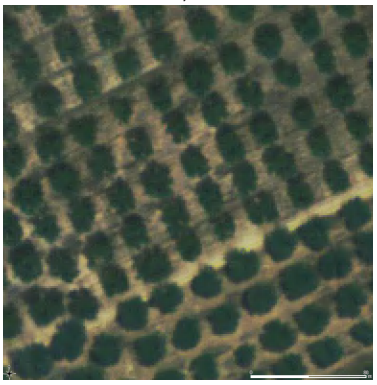

c)

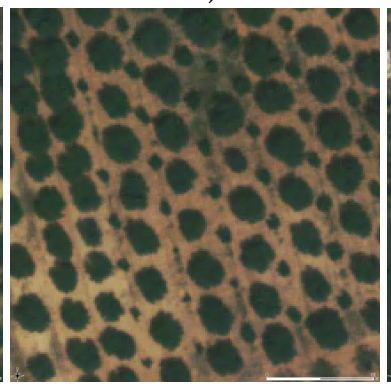

d)

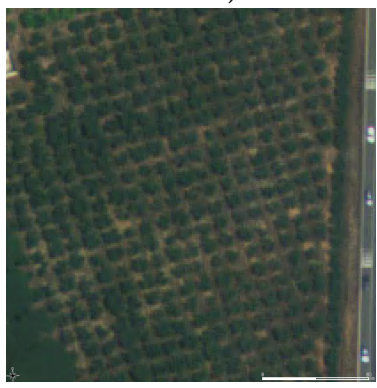

e)

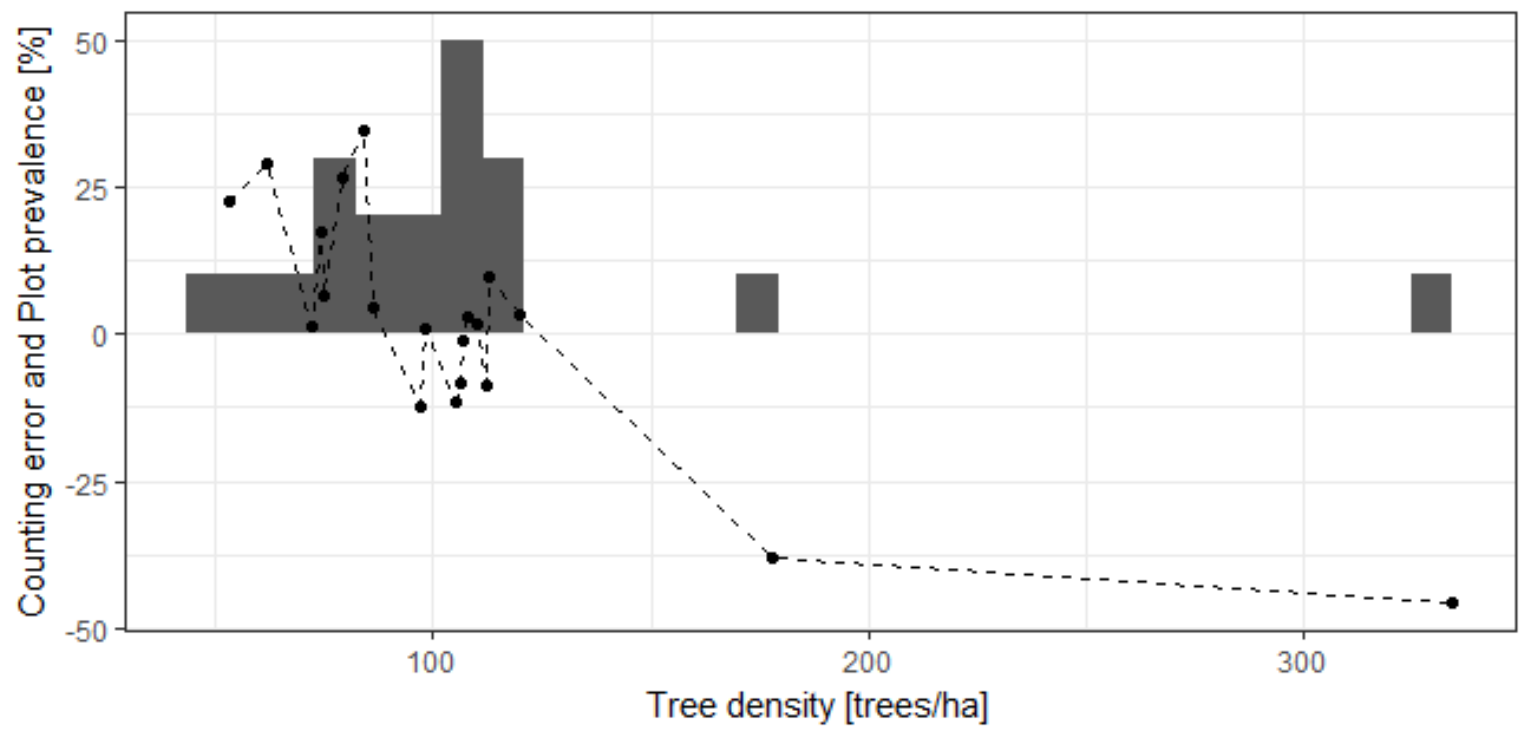

Figure 12. Examples of a) low tree-density (60 trees/ha), b) mid tree-density (94 trees/ha), (c) high tree-density with interplanting (138 trees/ha), and (d) very high tree-density olive plantations (370 trees/ha). All images cover 1 ha. e) Errors of the tree counting algorithm (dots) as a function of tree density. Counting errors using the 2015 image are shown for the 20 one-ha square plots comprising the reference area in Zone 1. Grey bars show the prevalence of different tree densities among the 20 plots.

\section{Discussion}

Estimates of tree numbers over large areas usually rely on combining estimates of tree cover density and tree cover extent [28]. Here, instead, we present a method to directly, rather than indirectly, count trees in a landscape using aerial photographs. The ongoing outbreak of Xylella fastidiosa in Southern Italy provided the direct impetus for this work, yet several pests are currently threatening tree species populations, (e.g. [29] [30]), creating an urgent need for tree monitoring tools. Mapping and counting the trees lost to such a disturbance shows its immediate impacts and enhances the precision and speed with which longer-term effects can be estimated, whether they are ecological (e.g. loss of diversity, carbon stock, or soil retention) or economical (e.g. loss of crops and productivity).

Xylella fastidiosa can cause complete canopy die-off within a year. In efforts to slow the impact and spread of the pathogen, olive trees in Apuglia are often severely pruned. Our algorithm explicitly focuses on mapping and counting intact tree crowns, excluding trees that are dead or recently and fully pruned. If they are healthy, the latter trees will redevelop a crown within a year. While image-based tree counts in any single year will thus reflect the extent of recent pruning activity, tree-level multi-year analysis will make it possible to distinguish pruned trees (based on their crown recovery), from trees with extensive canopy die-off, as caused by Xylella fastidiosa.

Intensely managed olive orchards tend to be even-aged, resulting in trees with similar crown sizes that are spaced along a relatively regular grid. In our study area in Apuglia, orchards are not 
intensively managed and some trees are more than 100 years old, while others were recently planted. This can result in locally highly variable crown sizes of trees, and an irregular distribution of trees within single orchards. Furthermore, ancient trees tend to lose branches at the center of their crown, which then splits into two or more clusters of branches. Finally, pruning can drastically change the appearance of tree crowns, as can differences in image resolution and viewing angles. The automated crown detection algorithm presented here performed well in the most common conditions, but suffered a loss in performance when tree density was exceptionally low or high. Areas with very low tree densities were characterized by old trees with complex, segmented, crowns, which can be difficult to unite analytically. Areas with very high tree densities are very few, but had a disproportionate effect on the error rates of the algorithm. In these areas, rows of young olive trees had been planted between rows of larger olive trees (a practice applied in the past in response to agricultural subsidies that were based on the number of olive trees cultivated), or the parcels were not olive monocultures, with citrus trees planted between the olive trees.

Understorey vegetation and intermixing of non-olive species vegetation can have a confounding effect on tree counting algorithms that rely solely on passive optical data, such as the one presented here; Similarities in radiance, particularly in broad spectral bands, between different tree species, grasses, and shrubs, can cause false positives in tree identification algorithms. Considering the phenology of overstorey as well as understorey vegetation in the acquisition of imagery can thus improve tree counts. In this study, the understorey in the 2016 image was considerably greener than in the 2015 image, despite both being acquired in May. However, this did not inflate our tree counts for 2016, compared to 2015, because there was sufficient difference in NDVI between the olive tree crowns and understorey species in both years. The few understorey areas that were mistaken for crowns, were often small (falling below the $<0.64 \mathrm{~m}^{2}$ threshold set for crowns) or large and homogenous (and therefore counted as one). Nonetheless, future research could address the distinction between different tree crops in single parcels, and both under and overstorey phenology should be considered when acquiring aerial photos for automated tree counting.

Local heterogeneity in tree sizes also exacerbates the difficulty of counting trees whose crowns form part of a semi-closed canopy, as no a-priori crown size can be assumed for individual trees. Our algorithm singles out image segments larger than $18 \mathrm{~m}^{2}$ and analyzes whether they are made up of crowns of multiple trees. When this does not appear the case, the segment is counted as a single crown. Some previous algorithms, and particularly OLICOUNT [8] were parcel-driven and semi-automatic, allowing an operator to set estimates of typical crown sizes for individual parcels. While manual tuning of the algorithm on a parcel-basis is unfeasible for wall-to-wall mapping, future development might investigate automated estimations of local crown size distributions to cope with the heterogeneity of olive tree sizes in Apuglia.

\section{Conclusions}

Here we have shown that it is feasible to count olive trees a landscape characterized by olive orchards with high heterogeneity, both between and within orchards, using aerial photographs. The method developed relies on a series of image segmentation and filtering operations, followed by iterative morphological analyses. Our results indicate that the method, while requiring further development to deal with particular plantation types, can be used to document both spatial and temporal variability in tree crown abundance. Indeed, the method is demonstrated using aerial images of different spatial resolutions, sensor characteristics, and seasons.

Next steps in the algorithm development could include the automated local optimization of parameters based on estimated crown size distributions and more refined masking of understorey and overstorey components with similar spectral characteristics to olive trees in order to deal with rare conditions that might inflate errors. The tree-counting algorithm can also be applied to other areas where trees form open or semi-open canopies, as is typical in agro-forestry systems. Most concretely, our findings show the possibility of using the existing wall-to-wall aerial photograph coverage of 
Apuglia to estimate the number of olive trees that are being lost as the Xylella fastidiosa epidemic progresses northward.

Acknowledgments: We thank Tina Caroppo for her technical assistance with the map of olive orchards, which was retrieved from the Geographic information system of the Puglia region (2016) at http:/ / www.sit.puglia.it/, and for providing the 2013 images. We thank Armando Cavazzini and CGR SPA for access to the 2015 and 2016 images and Juan Antonio Navas-Cortés for the photographs of olive trees taken in the field. We thank Donato Boscia for discussions on agricultural practices in the study area. This work was partially funded by the Horizon 2020 XF-ACTORS Project SFS-09-2016. The views expressed are purely those of the authors and may not in any circumstance be regarded as stating an official position of the European Commission.

Conflicts of Interest: The authors declare no conflict of interest.

\section{References}

1. Martelli, G.; Boscia, D.; Porcelli, F.; Saponari, M. The olive quick decline syndrome in south-east Italy: a threatening phytosanitary emergency. European Journal of Plant Pathology 2016, 144, 235-243.

2. Strona, G.; Carstens, C.J.; Beck, P.S. Network analysis reveals why Xylella fastidiosa will persist in Europe. Scientific Reports 2017, 7.

3. Almeida, R.P. Can Apulia's olive trees be saved? Science 2016, 353, 346-348.

4. EC. Council Directive 2000/29/EC: Plant Health Directives. , 2000.

5. White, S.M.; Bullock, J.M.; Hooftman, D.A.; Chapman, D.S. Modelling the spread and control of Xylella fastidiosa in the early stages of invasion in Apulia, Italy. Biological Invasions 2017, pp. 1-13.

6. Ke, Y.; Quackenbush, L.J. A comparison of three methods for automatic tree crown detection and delineation from high spatial resolution imagery. International Journal of Remote Sensing 2011, 32, 3625-3647.

7. Peters, J.; Van Coillie, F.; Westra, T.; De Wulf, R. Synergy of very high resolution optical and radar data for object-based olive grove mapping. International Journal of Geographical Information Science 2011, 25, 971-989.

8. Peedell, S.; Kay, S.; Giordino, G. Computer-assisted recognition of olive trees in digital imagery. Space Application Institute, Joint Research Center of Ispra, Italy 2000.

9. Masson, J.; Soille, P.; Mueller, R. Tests with VHR images for the identification of olive trees and other fruit trees in the European Union. Proceedings of SPIE, 2004, Vol. 5568, pp. 23-36.

10. Karantzalos, K.; Argialas, D. Towards automatic olive tree extraction from satellite imagery. Geo-Imagery Bridging Continents. XXth ISPRS Congress, 2004, pp. 12-23.

11. Daliakopoulos, I.N.; Grillakis, E.G.; Koutroulis, A.G.; Tsanis, I.K. Tree crown detection on multispectral VHR satellite imagery. Photogrammetric Engineering \& Remote Sensing 2009, 75, 1201-1211.

12. Bazi, Y.; Al-Sharari, H.; Melgani, F. An automatic method for counting olive trees in very high spatial remote sensing images. Geoscience and Remote Sensing Symposium, 2009 IEEE International, IGARSS 2009. IEEE, 2009, Vol. 2, pp. II-125.

13. González, J.; Galindo, C.; Arevalo, V.; Ambrosio, G. Applying image analysis and probabilistic techniques for counting olive trees in high-resolution satellite images. International Conference on Advanced Concepts for Intelligent Vision Systems. Springer, 2007, pp. 920-931.

14. Schindelin, J.; Arganda-Carreras, I.; Frise, E.; Kaynig, V.; Longair, M.; Pietzsch, T.; Preibisch, S.; Rueden, C.; Saalfeld, S.; Schmid, B.; others. Fiji: an open-source platform for biological-image analysis. Nature methods 2012, 9, 676-682.

15. Neteler, M.; Bowman, M.H.; Landa, M.; Metz, M. GRASS GIS: A multi-purpose open source GIS. Environmental Modelling \& Software 2012, 31, 124-130.

16. OSGeo. GDAL - Geospatial Data Abstraction Library, 2016.

17. K\&R, C.; Kernighan, B.W.; Ritchie, D.M. C programming language, 1988.

18. OpenMP. OpenMP Application Program Interface, 2013.

19. FSF. Bash [Unix shell program], 2016.

20. van Rossum, G. Python Language Reference, 2017.

21. Niblack, W. An introduction to digital image processing; Strandberg Publishing Company, 1985.

22. Sauvola, J.; Pietikäinen, M. Adaptive document image binarization. Pattern recognition 2000, 33, 225-236.

23. Helmy, I.M.; Azim, A.M.A. Efficacy of ImageJ in the assessment of apoptosis. Diagnostic pathology 2012, 7, 15 . 
24. Zarco-Tejada, P.J.; González-Dugo, V.; Berni, J.A. Fluorescence, temperature and narrow-band indices acquired from a UAV platform for water stress detection using a micro-hyperspectral imager and a thermal camera. Remote Sensing of Environment 2012, 117, 322-337.

25. Gonzalez-Dugo, V.; Zarco-Tejada, P.; Nicolás, E.; Nortes, P.; Alarcón, J.; Intrigliolo, D.; Fereres, E. Using high resolution UAV thermal imagery to assess the variability in the water status of five fruit tree species within a commercial orchard. Precision Agriculture 2013, 14, 660-678.

26. Braden, S. An Open Source Alternative for Crater Counting Using QGIS and the CircleCraters Plugin. Lunar and Planetary Science Conference, 2015, Vol. 46, p. 1816.

27. PugliaProvince. Geographical Information System online website, provided by Puglia authorities. http:/ / webapps.sit.puglia.it/freewebapps/DatiFasceXF/index.html, 2016.

28. Crowther, T.W.; Glick, H.; Covey, K.; Bettigole, C.; Maynard, D.; Thomas, S.; Smith, J.; Hintler, G.; Duguid, M.; Amatulli, G.; others. Mapping tree density at a global scale. Nature 2015, 525, 201.

29. Muirhead, J.R.; Leung, B.; Overdijk, C.; Kelly, D.W.; Nandakumar, K.; Marchant, K.R.; MacIsaac, H.J. Modelling local and long-distance dispersal of invasive emerald ash borer Agrilus planipennis (Coleoptera) in North America. Diversity and Distributions 2006, 12, 71-79.

30. Giblin-Davis, R.M.; Faleiro, J.R.; Jacas, J.A.; Peña, J.E.; Vidyasagar, P. Biology and management of the red palm weevil, Rhynchophorus ferrugineus. Potential invasive pests of agricultural crops (eds Peña JE) 2013, pp. 1-34. 